\title{
Application of Smart Education in College English Flipped Classroom
}

\author{
Cheng Liu ${ }^{1, a}$ and Xiaofang Wang ${ }^{2, b^{*}}$ \\ School of Humanities, Jiangxi University of TCM, No. 1688 of Meiling Road, Wanli District, \\ Nanchang City, Jiangxi Province, China \\ School of Humanities, Jiangxi University of TCM, No. 1688 of Meiling Road, Wanli District, \\ Nanchang City, Jiangxi Province, China \\ ajxjzlc@163.com, b920711622@qq.com \\ * The Corresponding Author
}

\section{Keywords: Smart education; College English; Flipped classroom; Teaching model}

\begin{abstract}
This paper gives a brief introduction to smart education, the flipped classroom teaching model and the main elements of the smart education environment of College English. The implementation plan of this research and the significance of intelligent education to the promotion of teaching work are introduced in detail. The research proves that the application of smart education in College English flipped classroom can greatly promote the quality and efficiency of teaching.
\end{abstract}

\section{The Definition of Smart Education and Flipped Classroom Teaching Model}

The idea of smart education was originally proposed from the perspective of philosophy, and its starting point and destination was to arouse and develop the wisdom of human beings. Later, although educators and psychologists enrich their connotation of smart education from their respective perspectives, they are still adhering to the traditional orientation of virtue and emotion. After the twenty-first Century, the rapid development of information technology has driven the smart education to the idea of technology, and has attracted more and more attention from Chinese scholars. Domestic scholars are essentially converging on the definition of the concept of smart education, but the emphasis is different. Jing Guoping (2003) compared smart education from its narrow meaning to its general meaning, he believes that the traditional smart education is to teach the students the system of scientific knowledge, development of skills and smart education and cultivating students' ability, and the general smart education is more comprehensive, rich, and diversified, and it is a unity of the rational wisdom, practical wisdom, and value wisdom. They are differentiated from each other and connected with each other. From the perspective of educational information, to Zhu Zhiting (2012) believes that the smart education is a new realm and new demands of education informationization, smart education needs Smart Learning Environments to be its technical support, with Smart Learning as the basic foundation and Smart Pedagogy as catalyst guiding. The combination of these three aspects is to cultivate and develop the learner's wisdom. Chen Lin (2015) also pointed out that smart education is the appropriate use of modern information technology to achieve smart education, smart learning, smart evaluation, intelligent management, smart service and improve students' high level thinking ability and innovative ability training. Huang Ronghuai (2014), from the viewpoint of system theory, argues that smart education is an education behavior system composed of schools, districts and nations. It provides high learning experience, high content adaptation and high efficiency of teaching, including the three levels of smart learning environment, new teaching mode and the modern education system.

The traditional teaching mode is that teachers teach in class, arrange homework, and let the students go home to practice. Different from the traditional classroom teaching mode, in the flipped classroom teaching mode students complete the learning at home, and classroom becomes the interaction place between teachers and students and among students, including answering questions, making use of knowledge, so as to achieve better educational results. The popularization of the Internet and the application of computer technology in the field of education make the flipping classroom teaching mode feasible and realistic. Students can use the Internet to use high quality 
education resources, and no longer rely solely on teachers to teach knowledge. The role of the class and the teacher has changed. The teachers' responsibility is to understand the students' problems and to guide the students to use knowledge.

\section{The Main Elements of the Smart Education Environment of College English}

In the perspective of smart education, College English needs to make full use of Internet information technology to build smart learning environment, to promote interaction between students and teachers, and make full use of Internet information learning resources, so as to achieve knowledge construction synergy. The famous scholar Zhong Zhixian once put forward: learning environment must include the activities, resources, environment and learning tools, Huang Ronghuai proposed learning environment mainly includes the composition of a variety of factors of resources, tools, teaching methods. We found that the smart environment of College English teaching must fully consider the factors of resources, tools, support and interaction, etc. The smart learning environment can effectively push and share personalized information, develop intelligent learning resources by using intelligent learning devices, develop and utilize the potential of intelligent learning, and improve the quality of intelligence learning. The community adopts intelligent learning mode to carry out man-machine interaction and interaction between teachers and students, so that students' learning and cooperation between teachers and students can be significantly improved and intelligent environment and information technology can be used to create a good learning environment.

\section{Research Implementation Scheme}

Our research objects are English class of 3A5 and it is selected as the experimental class, and English class 1A5 is a parallel control class. Both of them are in grade 2017.

At present, the university campus has basically realized the full network coverage, and online education and teaching resources and platforms can be used anytime and anywhere in the school. This study analyzed the learning needs of students from the students' learning ability, determined the starting point, the online learning goals, learning resources and learning content, making use of intelligent learning environment to lead students break the limit of textbooks and classroom in English learning, expand English learning from classroom to the outside, and promote students' effective learning both in the real and virtual situation context. The teacher provides a series of English learning resources for students, a specific arrangement of learning tasks, let students complete the task through mobile phones or computers, the establishment of WeChat groups, QQ groups, to exchange learning experience and experiences, realize timely interaction, dynamic tracking and evaluation of the learning process and effect of the students. And the specific research contents are as follows:

The students were divided into several groups, including 3-5 people in each group. One group leader was selected, who was mainly responsible for checking the completion of learning tasks, group learning preparation and group learning plan. The teachers share the teaching courseware and the related English learning audio, video and other materials, students can learn at anytime and anywhere in class. Teachers randomly check the completion of students' homework, record students' learning files, set up formative evaluation manuals, and make $30 \%$ achievements in the final exam, and guide students to learn actively.

Students are required to install VOA English learning software on the mobile phone (VOA Standard English), listening to 5 pieces of news every day extensively. They need to imitate and read two of the five pieces of news intensively, each about two minutes. A member of the study group is randomly selected to check other's learning. Teachers promptly pointed out and corrected the same problems of students, which aims to ensure the effectiveness of students' learning and their working hard for progress every day. VOA software with normal speed classifies all the news into different categories, updates practical news daily with Chinese translation, which can ensure the accuracy of students' reading. The software can be used online, and you can also download 
news after learning in the network environment, and support background playing. While listening and reading, we can click on any word for its definition, listen to the sound of the words and add to new word book. When in a network environment, automatic network will update to the interpretation the words of this view; through the law of memory processing for the previously stored words, students can master the words effectively. They can realize the sharing of the words in the web and mobile phone terminal end, and provide online dictionary query for the words used, help students to associate words when remembering the vocabulary. It also provides search function, search keywords of interest, search articles for listening and learning. It can be updated daily, obtain articles with the total amount more than 1000, support online and offline learning, record and analyze learning cases comprehensively. Students can intuitively grasp their own learning situation.

Students are required to install the software of Sea-Word Dictionary on their mobile phones, to complete the "daily hot words" and "daily situational learning" learning every day. They can make use of the random function of CET-4 words to learn 20 random words every day, which is done by the team members together, and the team leader is responsible for the examination of records.

The teacher uses the net of www.pigai.org to assign the writing and translation tasks once in two weeks. This website is the largest English composition and writing platform in China. This platform can submit the composition corrections timely for students, immediately give composition scores and the feedback analysis, which can facilitate students to correct the composition while the iron is hot. The platform can point out the existence of errors in each sentence, writing spelling, grammar and vocabulary, collocation errors, and also give suggestions to revise the composition where there are mistakes. This website provides users with specific knowledge of the expansion of training, collocation recommendation and reference example, and provides comprehensive writing guidance for students, which can help students' autonomous learning.

\section{Research Significance}

When smart education is used in flipped classroom for English teaching, it will be fully used. Students can learn English anytime and anywhere. Smart education can provide good English learning environment for students, improve their comprehensive English ability, and lay the foundation for students to learn at a higher level. And formative assessment and summative assessment can be combined. Teachers can implement diversified developmental evaluation, establish student growth archives, take students' long-term development as the basis, diagnose, motivate and strengthen the all-round development of students, scientifically and comprehensively evaluating students' English learning. Our research on this topic can optimize English flipped classroom teaching mode, arouse students' enthusiasm for English learning, and enable students to apply their knowledge to study, enhance students' learning motivation, optimize learning effect and improve the quality of English teaching.

\section{Conclusion}

The development and application level of educational informatization is increasingly becoming one of the core competitiveness of Chinese universities. The trend from digital campus to smart campus has become the trend and tide of the development of information technology in Higher Education in China. With the further impact of information technology and the "Internet plus" on education and infiltration, the continuous evolution of smart education, smart campus, future classroom. These education forms are changeable and will bring great changes to the College English learning environment for English learners and will also bring them more rich learning experience. Under this background, College English learning environment is the reconstruction of vision. Under the support of technology, it can preset real language learning and communication situations, automatic recognition of learner characteristics, target to provide learning resources and tools to automatically sense and record the learning process, reasonable evaluation of learning effect, and give timely and reasonable guide, to maximize the learning effectiveness and enthusiasm for learning English. This kind of learning environment is a virtual learning environment and personal learning environment 
of high-end form; it can realize the fusion of virtual environment and learning subject of learners in depth. It highlights the main position of learners in the learning process, attaches importance to the guiding role of teachers in the learning process, supports learners' social collaboration and communication, and effectively implements ubiquitous English learning. Therefore, this study suggests that the environment should be reconstructed with wisdom as the core of the learning environment of College English learning. From the demands of social informatization and school informatization to the change of learning environment, we can meet the diverse needs and individualized needs of College English learners, and achieve creative smart learning method for college English and achieve the best teaching results.

\section{Acknowledgements}

Research of Teaching Reform of Jiangxi Province in 2017 (No: JXJG-17-12-8); Research of Education Science Planning Projects of $13^{\text {th }}$ Five-Year in Jiangxi Province (No: 17YB145); Key Project of Teaching Reform of Jiangxi University of Traditional Chinese Medicine (No: 2016jzzd-1).

\section{References}

[1] Jing Guoping. From a narrow sense of smart education to a broad sense of smart education [J]. Journal of Hebei Normal University (Educational Science Edition), 2003, 5 (3): 48-53.

[2] Zhu Zhiting, He Bin. Smart education: the new realm of education information [J]. Audio-visual Education Research, 2012 (12): 5-13.

[3] Chen Lin, Chen Yaohua, Zheng Xudong. Smart education, China leading [J]. Audio-visual Education Research, 2015 (4): 23-27.

[4] Huang Ronghuai, Yang Junfeng, Hu Yongbin. Change and Trend of Learning Environment from Digital Learning Environment to Smart Learning Environment [J]. Open Education Research, 2012, 18 (1): 75-84. 